\title{
Report of the Nomenclature Committee for Fungi - 21: Lists from working groups $^{1}$
}

\author{
Tom W. May \\ gov.au
}

Royal Botanic Gardens Victoria, 100 Birdwood Avenue, Melbourne, Victoria 3004, Australia; corresponding author e-mail: tom.may@rbg.vic.

\author{
Key words: \\ accepted names \\ Ascomycota \\ Basidiomycota \\ conserved names \\ ICTF \\ International Code of Nomenclature \\ protected names
}

Article info: Submitted: 5 April 2017; Accepted: 21 April 2017; Published: 1 June 2017.

\section{LISTS OF NAMES FROM WORKING GROUPS}

This report concerns the lists from working groups set up under Art. 14.13 to deal en bloc with names of fungi considered to require conservation. For details of Nomenclature Committee for Fungi (NCFung) membership during the period when these lists have been considered, see Report of the NCFung 20 (Taxon 66: 483-495, 2017). Vote counts for approval of working groups and of lists are given, in order, as: votes for votes against - abstentions. The percentage of Yes votes is calculated from the total membership at the time of the ballot, which was 20 for approval of the working groups and 18 for approval of the lists. Working groups and lists were approved when the Yes vote was at least $60 \%$.

Two articles were introduced in the Melbourne International Code of Nomenclature for algae, fungi, and plants that provide for compilation of "lists of names" that "become Appendices of the Code once reviewed and approved by the Nomenclature Committee for Fungi and the General Committee". Article 14.13 deals with names that are "treated as conserved" and Art. 56.3 with names that are "treated as rejected". The two new articles were introduced in connection with changes to Art. 59 that removed the facility to legitimately name each of the different morphs of a single species for pleomorphic ascomycetous and basidiomycetous fungi. The two new articles cover "organisms treated as fungi" including lichenicolous fungi, but exclude "lichenforming fungi and those fungi traditionally associated with them taxonomically". Lists were introduced to facilitate the transition to "one fungus : one name" which was considered likely to involve numerous choices between different names based on anamorphic (asexual) and teleomorphic (sexual) morphs of the same fungus (although the use of lists is not limited to this situation). The examination of lists of names proposed to be treated as conserved or rejected under the two new articles is an addition to the established processes under Art. 14.1 and 56.1 that deal with individual names proposed for conservation or rejection.

The procedures used to approve the subcommittees (generally referred to as "working groups") and examine the lists produced have not matched the sequence set out in Art. 14.13 and 56.3, which state that lists are to be "submitted to the General Committee, which will refer them to the Nomenclature Committee for Fungi ... for examination by subcommittees established by that Committee in consultation with the General Committee and appropriate international bodies". Nevertheless, the NCFung has followed the intent of the Articles, guided by established practice in dealing with individual proposals. In relation to submission of lists, current practice for individual proposals is that publication of proposals in Taxon triggers consideration by the committees for the various taxonomic groups (such as the NCFung). Furthermore, it is publication of the reports of these committees that transmits their decisions to the General Committee (GC). Therefore, the same process has been followed in respect of the lists, except that the lists

${ }^{1}$ This report is being published in parallel in Taxon 66 (2) 496-499, 2017. Note that all recommendations in this and other reports of the Nomenclature Committee for Fungi are subject to approval by the General Committee on Nomenclature, which will report its' decisions in Taxon at a later date.

๑) 2017 International Mycological Association

You are free to share - to copy, distribute and transmit the work, under the following conditions:

Attribution: $\quad$ You must attribute the work in the manner specified by the author or licensor (but not in any way that suggests that they endorse you or your use of the work).

Non-commercial: $\quad$ You may not use this work for commercial purposes.

No derivative works: You may not alter, transform, or build upon this work.

For any reuse or distribution, you must make clear to others the license terms of this work, which can be found at http://creativecommons.org/licenses/by-nc-nd/3.0/legalcode. Any of the above conditions can be waived if you get permission from the copyright holder. Nothing in this license impairs or restricts the author's moral rights. 
have not been published in Taxon (see below). In relation to establishment of the subcommittees, Art. 14.13 and 56.3 state that lists are created first, then referred via the NCFung to the subcommittees. In reality, the subcommittees were approved and then the lists that they compiled were considered.

The working groups referred to as "subcommittees" in Art. 14.13 and 56.3 are established by the NCFung "in consultation with the General Committee and appropriate international bodies". The appropriate international body to consult is clearly the International Commission on the Taxonomy of Fungi (ICTF; http://www.fungaltaxonomy.org/). The ICTF is a COMCOF (Committees, Commissions and Federations) of the International Union of Microbiological Societies (IUMS) and the International Mycological Association (IMA). The ICTF has a membership of 25 , representing all continents, and works closely with the NCFung. The ICTF and NCFung currently have three members in common (Tom May, Scott Redhead, Marco Thines), including the current Chair (Redhead) and Secretary (May) of the NCFung. In addition, David Hawksworth is a member of the ICTF and the GC.

Implementation of working groups commenced at the "One Fungus = Which Name?" symposium, organised by the CBS Fungal Biodiversity Centre in Amsterdam, 12-13 April 2012 , and attended by 155 mycologists from 29 countries. The symposium was attended by NCFung Chair (Scott Redhead) and the then Secretary (Lorelei Norvell) as well as ICTF current Chair (Keith Seifert), incoming Chair (Conrad Schoch) and Secretary (Andrew Miller), along with David Hawksworth (GC, ICTF). Reports were presented on progress and issues for working groups on Basidiomycota, Dothideomycetes, Eurotiomycetes, Sordariomycetes (for which it was noted that several subgroups would be required) and Medical mycology (Hawksworth, IMA Fungus 3: (10)-(16), 2012a). The ICTF was recognised as the body responsible for coordination of working groups, through their formal subcommissions and newly established groups; with the NCFung and the GC (and eventually the Nomenclature Section) having ultimate responsibility for decisions about the names on the lists (Hawksworth, loc. cit., 2012a; Seifert \& Miller, IMA Fungus 3: (17)-(18), 2012). Guidance to working groups in compiling lists of names was provided by Hawksworth (IMA Fungus 3: 15-24, 2012b).

The ICTF has set up 21 international working groups (http://www.fungaltaxonomy.org/subcommissions/), formally approved at their meetings of 23 April 2015, 28 January 2016 and 6 March 2017. Some of these groups are existing subcommissions of the ICTF, some are affiliated commissions and some are de novo working groups, not necessarily intended to be permanent. Full membership of each group is indicated on the ICTF website (http://www.fungaltaxonomy. org/ictf-members/); see also individual publications of the groups (listed below).

The NCFung formally approved 20 of the 21 ICTF working groups under Art. 14.13 and 56.3 in several ballots during 2014 and 2016. The procedure adopted was to approve working groups if a $60 \%$ Yes vote was achieved, and if not, to leave the matter there (without requiring a $60 \%$ No vote or holding further ballots). The ICTF Oomycetes working group was not approved by NCFung under Art. 14.13 and 56.3 because this taxonomic group was not covered under the former Art. 59 (which dealt specifically with Ascomycota and Basidiomycota), and therefore there were no "one fungus : one name" issues to resolve.

The 20 international working groups approved by ICTF and NCFung at present are: (1) Five subcommissions of the ICTF - International Subcommission for the Taxonomy of Phytopathogenic Fungi (Co-chairs: Pedro Crous, Amy Rossman), International Subcommission on Colletotrichum Taxonomy (Chair: Lee Cai), International Subcommission on Fusarium Taxonomy (Chair: David Geiser), International Subcommission on Rust Taxonomy (Chair: M. Catherine Aime), International Subcommission on Trichoderma and Hypocrea (Chair: Irina Druzhinina), (2) the affiliated IUMS Commission - International Commission on Penicillium and Aspergillus (ICPA) (Chair: Rob Samson), and (3) 14 working groups (WGs) - Cordyceps WG (Convener: Joey Spatafora), Diaporthales WG (Convener: Amy Rossman), Dothideomycetes WG (Co-conveners: Pedro Crous, Kevin Hyde), Erysiphales WG (Convener: Uwe Braun), Heterobasidiomycetes WG (Convener: Dominik Begerow, see also International Subcommission on Rust Taxonomy, above), Homobasidiomycetes WG (Co-conveners: Tom May, Scott Redhead), Hypocreales WG (Co-conveners: Amy Rossman, Priscila Chaverri), Leotiomycetes WG (Convener: Peter Johnston), Medical Mycology WG (Convener: Sybren de Hoog), Miscellaneous fungi WG (Co-conveners: Conrad Schoch, Tom May), Orbiliomycetes WG (Convener: Hans-O. Baral), Pyricularia/Magnaporthe WG (Convener: Ning Zhang), Sordariomycetes excluding Diaporthales, Hypocreales and Magnaporthales WG (Co-conveners: Amy Rossman, Andrew Miller) and Yeast WG (Co-conveners: Clete Kurtzman, Jack Fell, affiliated with IUMS International Commission on Yeasts).

Introduction of the facility to submit names of fungi for conservation or rejection en bloc via lists was motivated in the first place by the removal of dual nomenclature for fungi, as is clear from the Preface to the Code which specifically mentions the intention "to minimize consequent nomenclatural disruption" from changes to Art. 59. However, Hawksworth (loc. cit. 2012b) pointed out that in fact lists can cover any fungus name (except for lichen-forming fungi). Kirk et al. (IMA Fungus 4: 381-443, 2013) published "A withoutprejudice list of generic names of fungi for protection under the International Code of Nomenclature ..." that listed 6995 generic names "as a first step towards the production of a List of Protected Generic Names for Fungi”, noting that while the ICTF was coordinating working groups, "the rates of progress have varied, and there are many orders and families with no working groups". However, the "without-prejudice list" was not produced by a formal working group of the ICTF. The NCFung formally voted on a "without-prejudice list" working group (whose membership was taken to be the authors of the publication) but such a working group was not approved [vote: $25 \%$ for approval] because in the initial phase of implementation of Art. 14.13 and 56.3 the NCFung wished to focus on the "one fungus : one name" issues, and preparation of a list of all genera in current use was considered to require more careful checking of citations and synonymy and wider consultation (see also below under Comprehensive lists of names for protection). 
This report deals with lists (as included in the cited publications) from the following six working groups: Cordyceps WG (Quandt et al., IMA Fungus 5: 121-134, 2014), Diaporthales WG (Rossman et al., IMA Fungus 6: 145-154, 2015), Dothideomycetes WG (Rossman et al., IMA Fungus 6: 507-523, 2015; replacing the earlier list of Wijayawardene et al., Fungal Diversity 69: 1-55, 2014), Hypocreales WG (Rossman et al., IMA Fungus 4: 41-51, 2013), Leotiomycetes WG (Johnston et al., IMA Fungus 5: 91-120, 2014) and International Subcommission on Trichoderma and Hypocrea (Bissett et al., IMA Fungus 6: 263-295, 2015). Assistance provided by the chairs and conveners of these six working groups (Priscila Chaverri, Pedro Crous, Irina Druzhinina, Kevin Hyde, Peter Johnston, Amy Rossman, Joey Spatafora) and the ICTF (through their Chair and Secretary, Conrad Schoch and Andrew Miller) in coordinating production of the lists and collaborative liaison with NCFung is acknowledged. Where the chair of the working group was not among the authors of publications, the official nature of the list has been confirmed with the relevant working group (as for the International Subcommission on Trichoderma and Hypocrea). Further lists from other working groups have recently been published or are in preparation.

The six lists dealt with in this report specifically designate the preferred name when there are choices of competing anamorph and teleomorph names for the one fungus, mostly at generic rank, but also including choices at family and species rank. It should be noted that the lists contain a mix of names that do and do not require formal action. Where the older of competing synonyms has been chosen, no formal action is required by the NCFung (except see "Article 57.2" below). It is only when a more recent name has been recommended over an older synonymous name that formal approval is required from the NCFung. Among cases requiring formal approval, only Art. 14.13 is involved (to treat names "as conserved") and no action under Art. 56.3 (to treat names "as rejected") has been proposed to date.

It should be noted that some cases to conserve names arising from "one fungus : one name" situations have been published as individual proposals under Art. 14.1. In fact, all recommendations for Erysiphales were published in this fashion (Braun, Taxon 62: 1328-1331, 2013) rather than submitted as a list; these proposals are dealt with in NCFung Report 20. Other cases have been presented as individual proposals and also included in the list from the relevant working group - specifically four proposals for names in Trichoderma (Prop. 2305, 2306, 2308, 2309) and the choice of Bipolaris over Cochliobolus (Prop. 2233). For such cases, the entries in the lists are approved below. How to deal with the individual proposals (such as by recommending to their authors that they be withdrawn) awaits clarification of the practical difference between "individual" conservation and inclusion in a list (see below).

The NCFung initially voted on the items in the six lists that required formal action, lumped together. Some members wished to vote on the set of items on each list separately, and therefore the lists were re-presented in this way in NCFung ballot 2016-2. Situations under Art. 57.2 were held over (see below). As a result, the following names in bold are proposed to be treated "as conserved" under Art. 14.13 against the accompanying names. Names are listed by working groups. The publications of the individual working groups (as cited above) should be consulted for publication and typification details of the names, as well as details for all cases of the choice of name adopted, including background information on relative usages. (S) denotes names typified by sexual morphs (teleomorphs) and (A) denotes names typified by asexual morphs (anamorphs).

\section{LIST FROM CORDYCEPS WG}

Votes: $14-1-3$ (78\% recommend approval of the list).

Ophiocordyceps Petch 1931 (S) against Sorosporella Sorokin 1888 (A), Hirsutella Pat. 1892 (A), Didymobotryopsis Henn. 1902 (A), Mahevia Lagarde 1917 (A), Synnematium Speare 1920 (A), Trichosterigma Petch 1923 (A), Didymobotrys Clem. \& Shear 1931 and (A) Hymenostilbe Petch 1931 (A) [The last two names are included for the moment, pending confirmation of their relative date of publication in relation to Ophiocordyceps Petch 1931].

\section{LIST FROM DIAPORTHALES WG}

Votes: $16-0-2$ (89\% recommend approval of the list).

Amphiporthe Petr. 1971 (S) against Amphicytostroma Petr. 1921 (A).

Apiognomonia Höhn. 1917 (S) against Discula Sacc. 1884 (A).

Melanconis Tul. \& C. Tul. 1863 (S) against Melanconium Link 1809 (A).

Pilidiella Petr. \& Syd. 1927 (A) against Schizoparme Shear 1923 (S).

Plagiostoma Fuckel 1870 (S) against Diplodina Westend. 1857 (A) and Septomyxa Sacc. 1854 (A).

\section{LIST FROM DOTHIDEOMYCETES WG}

Votes: $14-1-3$ (78\% recommend approval of the list). Note that one member commented "I vote no on Gemmamyces over Megaloseptoria. My yes applies to the rest."

Acrogenospora M.B. Ellis 1971 (A) against Farlowiella Sacc. 1891 (S).

Bipolaris Shoemaker 1959 (A) against Cochliobolus Drechsler 1934 (S). See also Prop. 2233 (Rossman et al. in Taxon 62: 1331-1332).

Botryosphaeria Ces. \& De Not. 1863 (S) against Fusicoccum Corda $1829(A)$.

Capnodium Mont. 1849 (S) against Polychaeton (Pers.) Lév. $1846(A)$.

Elsinoë Racib. 1900 (S) against Sphaceloma de Bary 1874 (A).

Gemmamyces Casagr. 1969 (S) against Megaloseptoria Naumov 1925 (A). 
Kirschsteiniothelia D. Hawksw. 1985 (S) against Dendryphiopsis S. Hughes 1953 (A).

Paranectriella (Henn. ex Sacc.) Höhn. 1910 (S) against Araneomyces Höhn. 1909 (A).

Phaeosphaeria I. Miyake 1909 (S) against Phaeoseptoria Speg. 1908 (A).

Podonectria Petch 1921 (S) against Tetracrium Henn. 1902 (A).

Venturia Sacc. 1882 (S) against Fusicladium Bonord. 1851 (A).

\section{LIST FROM HYPOCREALES WG}

Votes: $16-1-1$ (89\% recommend approval of the list).

Bionectriaceae Samuels \& Rossman 1999 (S) against Spicariaceae Nann. 1934 (A).

Hypocreaceae De Not. 1844 (S) against Trichodermataceae Fr. 1825 (A).

Hypomyces (Fr.) Tul. \& C. Tul. 1860 (S) against Sepedonium Link 1809 (A), Mycogone Link 1809 (A), Cladobotryum Nees 1817 (A) and Stephanoma Wallr. 1833 (A).

Nectria (Fr.) Fr. 1849 (S) against Tubercularia Tode 1790 (A).

Nectriaceae Tul. \& C. Tul. 1865 (S) against Tuberculariaceae Fr. 1825 (A).

Neonectria Wollenw. 1917 (S) against Cylindrocarpon Wollenw. 1913 (A).

Sphaerostilbella (Henn.) Sacc. \& D. Sacc. 1905 (S) against Gliocladium Corda 1840 (A).

\section{LIST FROM LEOTIOMYCETES WG}

Votes: $13-2-3$ (72\% recommend approval of the list).

Ascocalyx Naumov 1926 (S) against Bothrodiscus Shear 1907 (A) and Pycnocalyx Zap. 1916 (A).

Ascocoryne J.W. Groves \& D.E. Wilson 1967 (S) against Coryne Nees 1816 (A), Pirobasidium Höhn. 1902 (A), Pleurocolla Petr. 1924 (A) and Endostilbum Malençon 1964 (A).

Ascodichaena Butin 1977 (S) against Polymorphum Chevall. 1822 (A), Phloeoscoria Wallr. 1825 (A), Psilospora Rabenh. 1856 (A) and Dichaenopsis Paoli 1905 (A).

Blumeriella Arx 1961 (S) against Microgloeum Petr. 1922 (A) and Phloeosporella Höhn. 1924 (A).

Chlorociboria Seaver ex C.S. Ramamurthi et al. 1958 (S) against Dothiorina Höhn. 1911 (A).

Claussenomyces Kirschst. 1923 (S) against Dendrostilbella Höhn. 1905 (A).

Crumenulopsis J.W. Groves 1969 (S) against Digitosporium Gremmen 1953 (A).

Dematioscypha Svrček 1977 (S) against Schizocephalum Preuss 1852 (A) and Haplographium Berk. \& Broome $1859(A)$.

Dermea Fr. 1825 (S) against Sphaeronaema Fr. 1815 (A).

Diplocarpon F.A. Wolf 1912 (S) against Entomosporium Lév. 1856 (A), Bostrichonema Ces. 1867 (A), Morthiera Fuckel 1870 (A) and Marssonina Magnus 1906 (A).
Gloeotinia M. Wilson et al. 1954 (S) against Endoconidium Prill. \& Delacr. 1891 (A).

Godronia Moug. \& Lév. 1846 (S) against Sphaeronaema Fr. 1815 (A) and Topospora Fr. 1836 (A).

Godroniopsis Diehl \& E.K. Cash 1929 (S) against Sphaeronaema Fr. 1815 (A).

Gremmeniella M. Morelet 1969 (S) against Brunchorstia Erikss. 1891 (A).

Holwaya Sacc. 1889 (S) against Crinula Fr. 1821 (A).

Hypohelion P.R. Johnst. 1990 (S) against Leptostroma Fr. $1815(\mathrm{~A})$.

Leptotrochila P. Karst. 1871 (S) against Sporonema Desm. 1847 (A).

Monilinia Honey 1928 (S) against Monilia Bonord. 1851 (A).

Monochaetiellopsis B. Sutton \& DiCosmo 1977 (A) against Hypnotheca Tommerup 1970 (S).

Neofabraea H.S. Jacks. 1913 (S) against Phlyctema Desm. 1847 (A).

Pycnopeziza W.L. White \& Whetzel 1938 (S) against Acarosporium Bubák \& Vleugel ex Bubák 1911 (A) and Chaetalysis Peyronel 1922 (A).

Pyrenopeziza Fuckel 1870 (S) against Cylindrosporium Grev. 1822 (A) Cylindrodochium Bonord. 1851 (A).

Rhabdocline Syd. 1922 (S) against Meria Vuill. 1896 (A), Hartigiella Syd. \& P. Syd. 1900 (A) and Rhabdogloeum Syd. $1922(A)$.

\section{LIST FROM INTERNATIONAL SUB- COMMISSION ON TRICHODERMA AND HYPOCREA}

Votes: $16-1-1$ (89\% recommend approval of the list).

Hypocrea pezizoides Berk. \& Broome 1875 (S) against Trichoderma pezizoideum Wallr. 1833 (A). Note: the two epithets are considered confusable. See also Prop. 2308 (Samuels, Taxon 63: 936-938, 2014).

Trichoderma catoptron P. Chaverri \& Samuels 2004 (A) against Hypocrea catoptron Berk. \& Broome 1873 (S), H. sulfurella Kalchbr. \& Cooke 1880 (S) and $H$. flavovirens Berk. 1884 (S). See also Prop. 2305 (Samuels, loc. cit.).

Trichoderma citrinoviride Bissett 1984 (A) against Sphaeria schweinitzii Fr. 1828 (S), S. contorta Schwein. 1832 (S), Hypocrea repanda Fuckel 1871 (S) and H. minima Sacc. \& Ellis 1882 (S). See also Prop. 2306 (Samuels, loc. cit.).

Trichoderma gelatinosum P. Chaverri \& Samuels 2003 (A) against Sphaeria cupularis Fr. 1830 (S) and Hypocrea moriformis Cooke \& Massee 1888 (S).

Trichoderma reesei E.G. Simmons 1977 (A) against Hypocrea jecorina Berk. \& Broome 1873 (S). See also Prop. 2309 (Samuels, loc. cit.).

Article 14.13 specifies that, once approved, lists of names "become Appendices of the Code". Given the novel nature of the lists from working groups, the manner in which this is done will need to be worked out. Names from lists could be integrated into existing appendices, perhaps denoted as arising from lists rather than the individual proposals that led to other entries. The matter of whether or not there is any practical difference for names from lists as compared to those 
from individual proposals will need clarification (see below) and it also needs to be kept in mind that lists are not restricted to "one fungus : one name" situations (see below).

\section{THE DIFFERENCE BETWEEN CONSERVED AND TREATED AS CONSERVED}

Currently, it is not clear what is the practical difference between "individual" conservation under Art. 14.1 and inclusion in a list under Art. 14.13 leading to names being treated "as conserved"; and the same for names rejected under Art. 56.1 and "treated as rejected" under Art. 56.3. Hawksworth (Ioc. cit. 2012a) recognised that there was potential for confusion, and, using the term "Accepted Lists" for lists from working groups, indicated that the difference between individual conserved names (under Art. 14.1) and names dealt with in lists under Art. 14.13 is that "names included in the Lists of Conserved Names [i.e., in the Code Appendices, arising from individual conservation] ... have precedence over those on the Accepted Lists", and "names that are formally conserved cannot be deleted, whereas there is no such restriction for names on the Accepted Lists". Hawksworth (loc. cit., 2012b) further pointed out that it is not clear whether or not the lists from working groups remain open, such as by addition or revision of names, an option which he favoured so as to "enable them to be added to as detailed treatments of families and genera become available". This latter point is more relevant to comprehensive lists (see below) rather than the current phase of resolution of "one fungus : one name" issues. Hawksworth (Taxon 64: 858-862, 2015) introduced proposals to amend the Code so that the terms "accepted" and "rejected" in Art. 14.13 and 56.3 would be replaced by "protected" and "suppressed" respectively, and furthermore that, in relation to Art. 14.13, conservation specifically overrides "protection" and the lists of protected names "remain open for revision". It would be beneficial to have examples clarifying the difference in practice between "conserved" and "protected" and "rejected" and "suppressed" under the current wording and proposed wordings of the Code.

\section{COMPREHENSIVE LISTS OF NAMES FOR PROTECTION}

It is important to note that Art. 14.13 and 56.3 allow for not only lists arising from resolution of "one fungus : one name" issues, but in fact lists of any names or indeed all names of fungi (for non-lichen taxa). In the opinion of the NCFung, the potentially wide application of lists is not well-understood by the mycological community, and implementation of the articles in this broad sense requires further discussion and establishment of clear procedures. This report focuses on "one fungus : one name" issues as it is important to stabilise names of pleomorphic fungi affected by the changes in Art. 59. Once all working groups have reported or indicated that they have no matters for formal consideration in relation to "one fungus : one name" issues, the NCFung will move on to consideration of any comprehensive lists intended for wholesale adoption under Art. 14.13.

It is noted that some comprehensive lists have been published, such as for Penicillium (Visagie, Stud. Mycol. 78: 343-371, 2014), where it is unclear whether or not it is intended that all names be considered under Art. 14.13, while in one case, for Trichoderma, authors of a comprehensive list have explicitly stated that they "wish all names published prior to 1 January 2013 and accepted here to be included in the eventual list of protected names as soon as that is permitted by the ICN" (Bissett et al., loc. cit.). At the moment, only those entries in lists (from formally constituted working groups) that take up a later name over an earlier name have been selected for approval above, because for other names, normal priority operates in any case (see also "Article 57.2" below). However, it should be noted that Hawksworth (loc. cit., 2015) has proposed to amend the Code so that names submitted via lists be protected not only from listed names but also from unlisted names, which will mean that formal approval of comprehensive lists would have additional practical consequences.

Some lists include citation of type material but not necessarily with consistent indication of whether holotype, lectotype or neotype. How these type citations, which are of great importance for stability, should be presented when lists are formally adopted is another area where further clarification is required. There is clearly a role for comprehensive and authoritative lists prepared by international working groups, and implementation of such lists in conformity with the Code will be an important task for NCFung and ICTF once this first phase of implementation of the transition to "one fungus : one name" has been completed.

\section{ARTICLE 57.2}

Under the Code as it stands, formal action is required where an earlier anamorph-typified name is chosen as the preferred name over a later teleomorph-typified name. Article 57.2 requires a specific but rather confusing action by the NCFung prior to taking up an earlier anamorphtypified name over a later synonymous teleomorph-typified name. That action is rejection by the NCFung of a proposal (either individually or as part of a list) to (1) conserve the later name over the earlier name or (2) reject the earlier name outright. However, there is almost unanimous support from mycologists to remove this article from the Code, and let priority rule, whether or not the earlier name is anamorph- or teleomorph-typified (May, IMA Fungus 6(2): (43)-(44), 2015). A formal proposal to amend the Code to this affect has been published (Hawksworth, loc. cit., 2015) and it is highly likely that Art. 57.2 will be deleted from Code as a result of deliberation during the Nomenclature Section at the Shenzhen IBC in 2017. In the interim, all cases that fall under Art. 57.2, whether involving a list from a working group or individual proposals (or indeed where authors have made choices without realising that Art. 57.2 should be invoked), will be dealt via the Miscellaneous Fungi WG who will present a consolidated list to the NCFung. 
SYNTHESIS OF "ONE FUNGUS : ONE NAME" RESOLUTIONS

It is important to note that the choices of names listed above as being formally approved by the NCFung are a subset of numerous choices resulting from the move to "one fungus : one name"; being only those situations where formal action is required due to taking up a later name over an earlier name. Other choices are detailed in the publications of the working groups and indeed scattered throughout recent mycological literature. It is the intention of the NCFung/ICTF to compile all cases in an aggregate publication in due course. 